\title{
EFEITO DOS PERÍODOS DE ENVELHECIMENTO NA LIXIVIAÇÃO DE ÍONS E DE PROTEÍNAS SOLÚVEIS EM SEMENTES DE MILHO ${ }^{1}$
}

\author{
ELZA ALVES ${ }^{2}$, CLÁUDIO CAVARIANI ${ }^{3}$, MARCELO ROCHACORREA ${ }^{2}$, FABIANY LILYANI GONÇALVES SOUZA $^{4}$, \\ TIAGO MATTOSINHO CORRÊA², JOÃO NAKAGAWA ${ }^{5}$
}

\begin{abstract}
RESUMO - Este trabalho foi conduzido no Laboratório de Análise de Sementes, do Departamento de Produção Vegetal, da Universidade Estadual Paulista (Botucatu/SP), com o objetivo de avaliar os efeitos causados por diferentes períodos de envelhecimento acelerado na lixiviação de íons e de proteínas solúveis em sementes de milho. Sementes de milho do híbrido BR 3123 foram colocadas sobre tela em gerbox, contendo $40 \mathrm{~mL}$ de água destilada, e mantidas a temperatura de $42^{\circ} \mathrm{C}$ por períodos de 0, 24, 48, 72, 96, 120, 144 e 166 horas. Após o envelhecimento, parte das sementes foi colocada para germinar, empregando quatro repetições para cada período, obtendo-se a porcentagem de plântulas normais no quarto dia. Em outra parte realizou-se, após manutenção em copos plásticos com $75 \mathrm{~mL}$ de $\mathrm{H}_{2} \mathrm{O}$ destilada por 24 horas à $25^{\circ} \mathrm{C}$, leituras de condutividade elétrica $\left(\mu \mathrm{S} . \mathrm{cm}^{-1} \cdot \mathrm{g}^{-1}\right)$, determinação de íons $\left(\mathrm{mg} \cdot \mathrm{L}^{-1} \cdot \mathrm{g}\right.$ de semente $\left.{ }^{-1}\right)$ e de proteínas solúveis totais ( $\mu$ proteina. $\mathrm{g}^{-1} \cdot \mathrm{mL}^{-1}$ ) lixiviadas na solução. Os resultados indicaram que a elevação dos valores de condutividade elétrica e de lixiviado de proteínas totais ocorreu a partir de 72 horas de envelhecimento acelerado. A lixiviação de potássio foi mais acentuada que a dos íons cálcio, zinco, manganês, cobre, ferro e magnésio.
\end{abstract}

Termos para indexação: Zea mays, germinação, condutividade elétrica.

\section{EFFECT OF DIFFERENT PERIODS OF ACCELERATED AGING ON CORN PHYSIOLOGICAL SEED QUALITY AND ÍONAND SOLUBLE PROTEIN LEAKAGE}

\begin{abstract}
This experiment was carried out at the Seed Analysis Laboratory of the Plant Production Department of the Universidade Estadual Paulista (UNESP/Botucatu) with the purpose to evaluate different periods of accelerated aging on ion and soluble protein leakage in seed quality. Corn seeds of the BR 3123 cultivar were put in a gerbox with $40 \mathrm{~mL}$ distilled water at $42^{\circ} \mathrm{C}$ to periods of zero, 24, 48, 72, 96, 120, 144 and 166 hours. After aging, part of these seeds was submitted to a germination test with 4 replicates for each period, and count of normal seedlings was made on the $4^{\text {th }}$ day after. Another part of these seeds was soaked in $75 \mathrm{~mL}$ distilled water for 24 hours at $25^{\circ} \mathrm{C}$ and electrical conductivity $\left(\mu \mathrm{S} . \mathrm{cm}^{-1} \cdot \mathrm{g}^{-1}\right)$, ions determination $\left(\mathrm{mg} \cdot \mathrm{mL}^{-1} \cdot \mathrm{g}\right.$ of seed $\left.\mathrm{s}^{-1}\right)$ and total soluble protein leakage ( $\mu$ protein. $\mathrm{g}^{-1} \cdot \mathrm{mL}^{-1}$ ) was determined in the solution. It was verified that. Potassium leakage was higher than $\mathrm{Ca}, \mathrm{Zn}, \mathrm{Mn}, \mathrm{Cu}, \mathrm{Fe}$ and $\mathrm{Mg}$ ions.
\end{abstract}

Index terms: Zea mays, germination, electrical conductivity

\footnotetext{
${ }^{1}$ Submetido em 24/11/2003. Aceito para publicação em 16/06/2004

${ }^{2}$ Alunos do PPG-Agricultura, Departamento de Produção Vegetal-Setor Agricultura, FCA/UNESP. Botucatu/SP.

${ }^{3}$ Prof. Dr. Departamento de Produção Vegetal-Setor Agricultura, FCA/
}

UNESP,108603-970 Botucatu SP.

${ }^{4}$ Aluna Iniciação Científica; Bolsista FAPESP_Curso de Agronomia; FCA/ UNESP. Botucatu/SP.

${ }^{5}$ Prof. Titular Aposentado, Voluntário, Bolsista do CNPq. 


\section{INTRODUÇÃO}

O vigor é o reflexo de um conjunto de fatores que determina o potencial fisiológico das sementes (Marcos Filho, 1999), sendo que a deterioração, processo que o influencia diretamente, tem início imediatamente após a maturidade fisiológica e prossegue enquanto as sementes permanecem no campo, durante a colheita, beneficiamento e armazenamento.

A desestruturação dos sistemas de membranas em nível celular tem sido relatada como a conseqüência inicial da deterioração (Abdel Samad \& Pearce, 1978). Assim a elucidação dos mecanismos envolvidos em tal processo é de grande importância para os estudos que buscam informações sobre a perda da qualidade fisiológica das sementes.

O aumento da lixiviação de compostos orgânicos na solução de embebição, está diretamente relacionado com o decréscimo da viabilidade e do vigor destas sementes. Sendo que a escarificação ou qualquer tipo de dano no tegumento da semente pode aumentar a lixiviação de várias substâncias do embrião (Abdel Samad \& Pearce, 1978).

As reações oxidativas são responsáveis pela deterioração das sementes (Flood \& Sinclair, 1981; Ohlrogge \& Kernan, 1982) sendo que essas reações ocorrem por auto-oxidação ou peroxidação em processo não enzimático (Harrington, 1973). A oxidação de ácidos graxos insaturados é citada, muitas vezes, como a primeira reação no processo de envelhecimento, produzindo radicais livres que, subseqüentemente, atacam lipídios, proteínas e ácidos nucléicos, com reações em cadeia (Harrington, 1973). Também tem sido amplamente sugerido na literatura que as reações oxidativas do processo de envelhecimento podem envolver enzimas como lipoxigenases, além da possibilidade da deterioração em sementes armazenadas ser induzida por processo enzimático (Abdel Samad \& Pearce, 1978).

$\mathrm{Na}$ atualidade, um dos requisitos básicos para avaliação do vigor das sementes refere-se à obtenção de resultados confiáveis em um período de tempo relativamente curto, uma vez que as tomadas de decisões devem ser agilizadas, principalmente no que se refere às operações de colheita, beneficiamento e comercialização.

Dentre os métodos considerados rápidos para avaliação de vigor de sementes, destacam-se aqueles baseados na integridade das membranas celulares, como os testes de condutividade elétrica, os quais fornecem resultados em 24 horas (McDonald Jr. \& Wilson, 1980; Matthews \& Powell, 1981; Marcos Filho et al.,1990). Além desses, o teste de lixiviação de íons, dentre eles o potássio, baseia-se em princípios semelhantes, com a vantagem adicional de proporcionar informações sobre a qualidade fisiológica dos lotes, em períodos de tempo consideravelmente reduzidos em relação ao teste de condutividade (Dias \& Marcos Filho, 1995).

Dias \& Marcos Filho (1995) citam ainda, que a concentração total de eletrólitos liberados pelas sementes durante a embebição tem sido avaliada indiretamente, principalmente através do teste de condutividade elétrica, considerando-se que porção significativa desses eletrólitos é representada por vários íons inorgânicos. Estudos têm sido conduzidos visando determinar a liberação de cátions específicos durante a embebição, bem como a lixiviação de proteínas solúveis, que são as principais responsáveis pelos processos metabólicos nas sementes. Além disso, pesquisas têm sido conduzidas no sentido de obter informações sobre as principais mudanças que ocorrem durante a deterioração (Abdel Samad \& Pearce, 1978; McDonald Jr \& Wilson, 1980; Matthews \& Powel, 1981; Dias \& Marcos filho, 1995).

Para tanto, este trabalho foi realizado com o objetivo de avaliar os efeitos causados por diferentes períodos de envelhecimento artificial na lixiviação de íons e de proteínas solúveis em sementes de milho.

\section{MATERIALE MÉTODOS}

O estudo foi conduzido no Laboratório de Análise de Sementes da Faculdade de Ciências Agronômicas da Universidade Estadual Paulista (FCA/UNESP), Botucatu-SP. Os tratamentos constaram de sementes de milho híbrido BR 3123 , classificadas em peneira de crivo circular 22/64" $(8,73 \mathrm{~mm})$, submetidas a sete períodos de envelhecimento artificial e avaliadas quanto à germinação, à condutividade elétrica e à lixiviação de íons e de proteínas solúveis totais.

$\mathrm{O}$ grau de umidade das sementes foi determinado em duas repetições de 50 sementes, pelo método de estufa a 105 $\pm 3^{\circ} \mathrm{C}$ por 24 horas, de acordo com as Regras para Análise de Sementes (Brasil, 1992).

Para o envelhecimento acelerado, as sementes foram colocadas em caixas de Gerbox adaptadas, contendo $40 \mathrm{~mL}$ de água destilada, sendo distribuídas em camada única sobre tela de metal. Em seguida, as caixas foram fechadas e levadas a uma câmara de germinação do tipo BOD, regulada à temperatura de $42^{\circ} \mathrm{C}$ durante períodos de $0,24,48,72,96$, 120, 144 e 166 horas. Após cada período de envelhecimento, quatro subamostras de 50 sementes foram colocadas para germinar entre três folhas de papel germitest umedecidas com água destilada, 2,5 vezes o peso do papel seco. Foram 
confeccionados rolos, sendo mantidos em germinador a $25^{\circ} \mathrm{C}$ (Brasil, 1992). As avaliações foram feitas aos quatro dias após a semeadura e os resultados expressos em porcentagem média de plântulas normais.

O teste de condutividade elétrica foi realizado utilizandose quatro subamostras de 50 sementes para cada período de envelhecimento, as quais foram pesadas e colocadas em um recipiente com $75 \mathrm{~mL}$ de água destilada e mantidas em câmara de germinação a $25^{\circ} \mathrm{C}$ por 24 horas. Após esse período, foi feita a leitura da condutividade elétrica da solução do exsudato com auxílio de condutivímetro Digimed DM 31, expressa em $\mathrm{mS} \cdot \mathrm{cm}^{-1} \cdot \mathrm{g}^{-1}$ de sementes em função do peso inicial das sementes utilizadas (AOSA, 1983).

A partir dos exsudatos obtidos no teste de condutividade elétrica, foram determinadas as concentrações dos eletrólitos zinco $(\mathrm{Zn})$, manganês $(\mathrm{Mn})$, cobre $(\mathrm{Cu})$, cálcio $(\mathrm{Ca})$, ferro $(\mathrm{Fe})$, magnésio $(\mathrm{Mg})$ e potássio $(\mathrm{K})$ em espectrofotômetro de absorção atômica, nos comprimentos de onda de 213, 279, $324,422,248,285$ e 766nm, respectivamente. Os resultados foram expressos em $\mathrm{mg} \cdot \mathrm{L}^{-1} \cdot \mathrm{g}^{-1}$ de semente.

O conteúdo de proteína solúvel total foi determinado de acordo com o método proposto por Lowry et al. (1951), em amostra de $0,5 \mathrm{~mL}$ da solução de exsudados obtida no teste de condutividade elétrica. O sistema de reação foi montado com a adição de $5 \mathrm{~mL}$ de uma solução reativa contendo $\mathrm{Na}_{2} \mathrm{CO}_{3}, \mathrm{NaOH}, \mathrm{CuSO}_{4} .5 \mathrm{H}_{2} \mathrm{O}$ e $\mathrm{KNaC}_{4} \mathrm{H}_{4} \mathrm{O}_{6} .4 \mathrm{H}_{2} \mathrm{O}$, conforme proposto pelo referido autor. Após 15 minutos de repouso, foi adicionado $0,5 \mathrm{~mL}$ do reativo de Folin, sendo mantido em banho-maria a $25^{\circ} \mathrm{C}$ durante 30 minutos, e realizada leitura em espectrofotômetro de UV visível no comprimento de onda de $660 \mathrm{~nm}$. Os resultados foram expressos em mg. $\mathrm{g}^{-1} \cdot \mathrm{mL}^{-1}$.

$\mathrm{O}$ delineamento experimental utilizado foi inteiramente casualizado, com quatro repetições e as médias foram comparadas pelo teste de Tukey, a de $5 \%$ de probabilidade.

\section{RESULTADOS E DISCUSSÃO}

Os dados obtidos na variável germinação, conforme Figura 1, revelam que a porcentagem de plântulas normais foi reduzida a partir de 96 horas de envelhecimento, o que corrobora citação feita por Marcos Filho (1999).

Com relação aos resultados do teste de condutividade elétrica apresentados na Figura 2, os períodos de 24, 48 e 72 horas não diferiram estatisticamente da testemunha $(0 \mathrm{~h})$, sendo observadas diferenças apenas a partir de $96 \mathrm{~h}$ de envelhecimento com maiores lixiviações de solutos para a solução de embebição das sementes. Esse fato foi verificado por Woodstock (1988) que considerou a exsudação de constituintes celulares inversamente associado ao vigor, refletindo na perda da compartimentalização dos constituintes celulares em decorrência da perda da integridade das membranas. Desse modo, a desestruturação e perda de integridade do sistema de membranas celulares, causadas principalmente pela oxidação de lipídios, promove o descontrole do metabolismo e das trocas de água e solutos entre as células e o meio exterior, com reflexos diretos sobre a qualidade fisiológica das sementes.

Na Figura 3 estão apresentados os resultados referentes à lixiviação de proteínas solúveis totais. A partir de $144 \mathrm{~h}$ de envelhecimento houve diferença significativa em relação à testemunha, sugerindo que a lixiviação de proteína não apresenta correlação com a porcentagem de germinação, ao contrário do observado por Alizaga et al. (1990) que, ao estudar lixiviação de aminoácidos em sementes de feijão, observaram separação das amostras segundo sua qualidade fisiológica, classificando-as em diferentes níveis de vigor.

De acordo com Chanhan et al. (1984) e Bewley (1986), o aumento da lixiviação de compostos citoplasmáticos, quando as sementes são colocadas em água, pode ser atribuído a alterações nas configurações das membranas celulares, devido a deterioração provocar danos nos mecanismos de reparo. Desta forma a deterioração das sementes pode ser medida através da qualidade de compostos lixiviados.

Conforme apresentado nas Figuras 4 e 5, na lixiviação de $\mathrm{Cu}$ e $\mathrm{Ca}$, não foi possível detectar diferenças entre os períodos de envelhecimento. Para o íon $\mathrm{Zn}$, as maiores lixiviações foram observadas a partir de 48 horas. $\mathrm{Mg}$ e $\mathrm{Mn}$ apresentaram os maiores valores de lixiviação às 24 e 166 horas, respectivamente, o que não corrobora os dados obtidos por Woodstock et al. (1985), os quais observaram que a liberação dos íons $\mathrm{Mn}, \mathrm{Mg}$ e $\mathrm{Ca}$ está relacionada com deterioração em sementes de algodão. O mesmo comportamento foi observado por Oliveira (1990) em sementes de soja ao estudar a liberação de $\mathrm{Ca}, \mathrm{Mg}$ e $\mathrm{Na}$.

Com relação ao $\mathrm{K}$ (Figura 6), apesar de não ter sido observado diferença estatística até as 120 horas, podemos observar que houve uma tendência de aumento nos valores de lixiviação, a partir de 96h de envelhecimento, em relação à testemunha. Conforme trabalhos realizados por Halloin (1975), McKersie \& Stinson (1980) e Woodstock et al. (1985), a quantidade de $\mathrm{K}$ liberado por sementes embebidas tem sido utilizada como indicador da integridade do sistema de membranas celulares.

Em sementes de amendoim, Abdel Samad \& Pearce (1978) observaram aumentos gradativos na lixiviação deste 


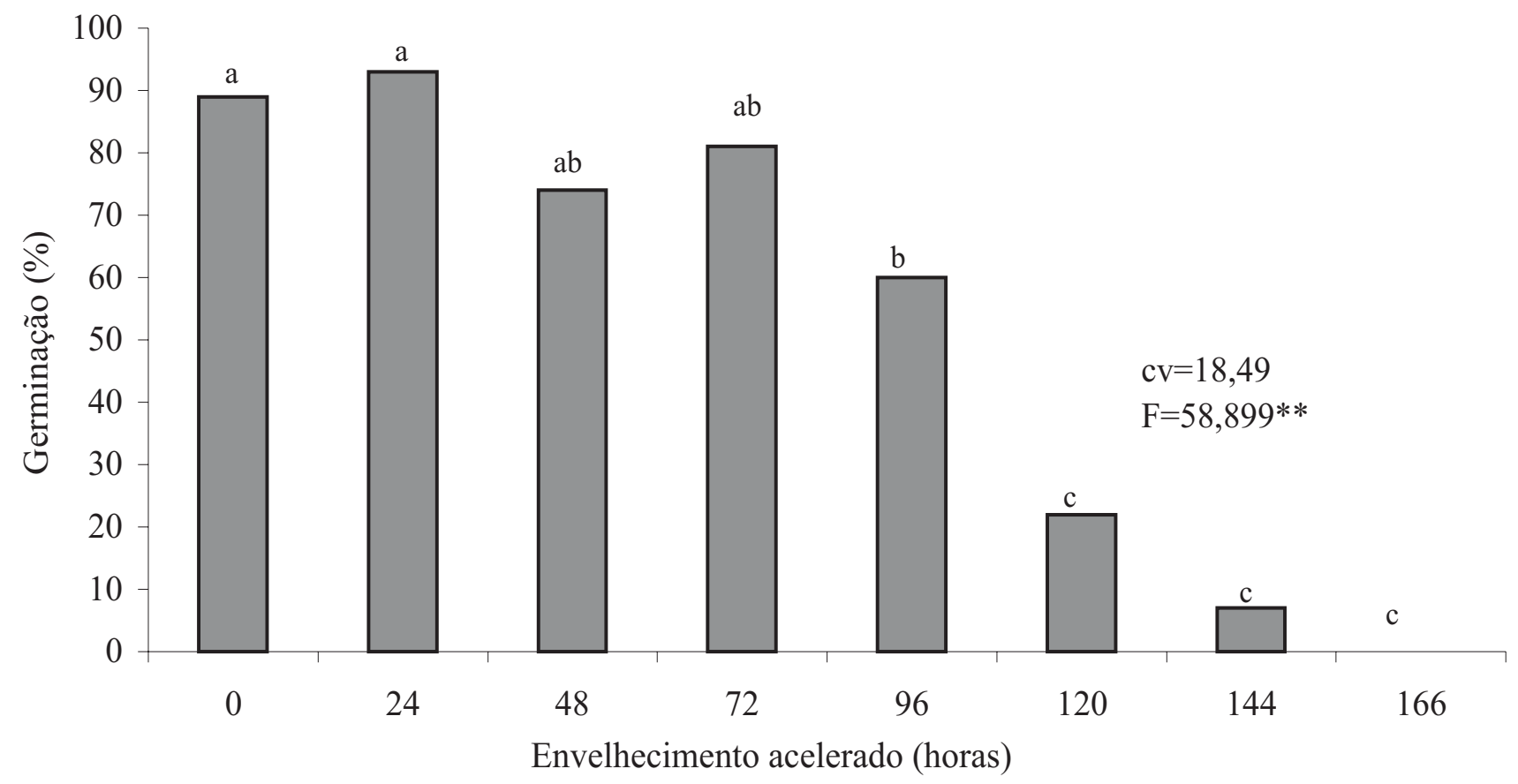

FIGURA 1. Germinação (\%) de sementes de milho BR 3123, submetidas a diferentes períodos de envelhecimento acelerado. Botucatu/SP, 2003.

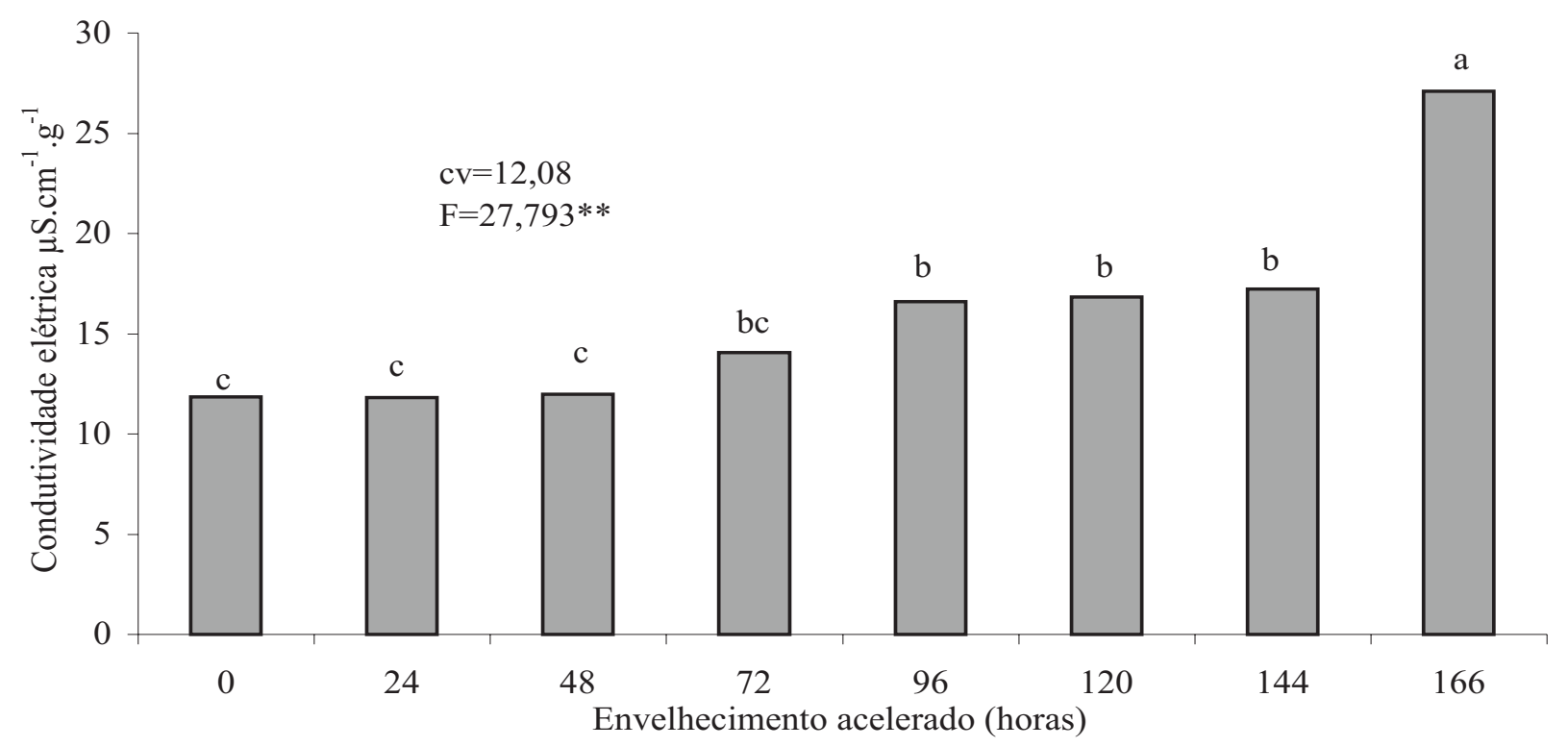

FIGURA 2. Condutividade elétrica $\left(\mu \mathrm{S} . \mathrm{cm}^{-1} \cdot \mathrm{g}^{-1}\right)$ de sementes de milho BR 3123, submetidas a diferentes períodos de envelhecimento acelerado. Botucatu/SP, 2003. 


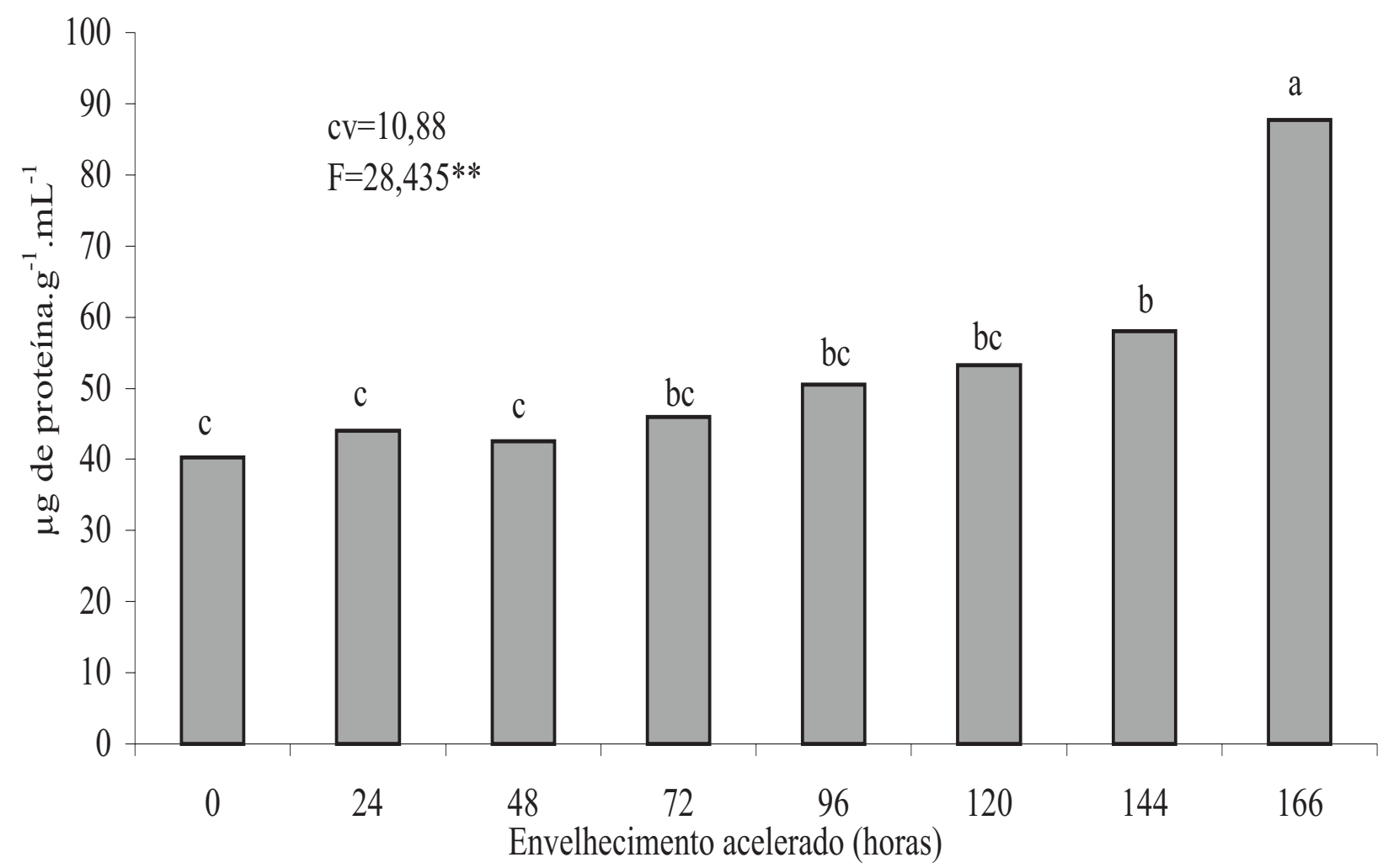

FIGURA 3. Proteína solúvel total ( $\mu$ g de proteína. $\left.\mathrm{g}^{-1} \cdot \mathrm{mL}^{-1}\right)$ lixiviada de sementes de milho BR 3123, submetidas a diferentes períodos de envelhecimento acelerado. Botucatu/SP, 2003.

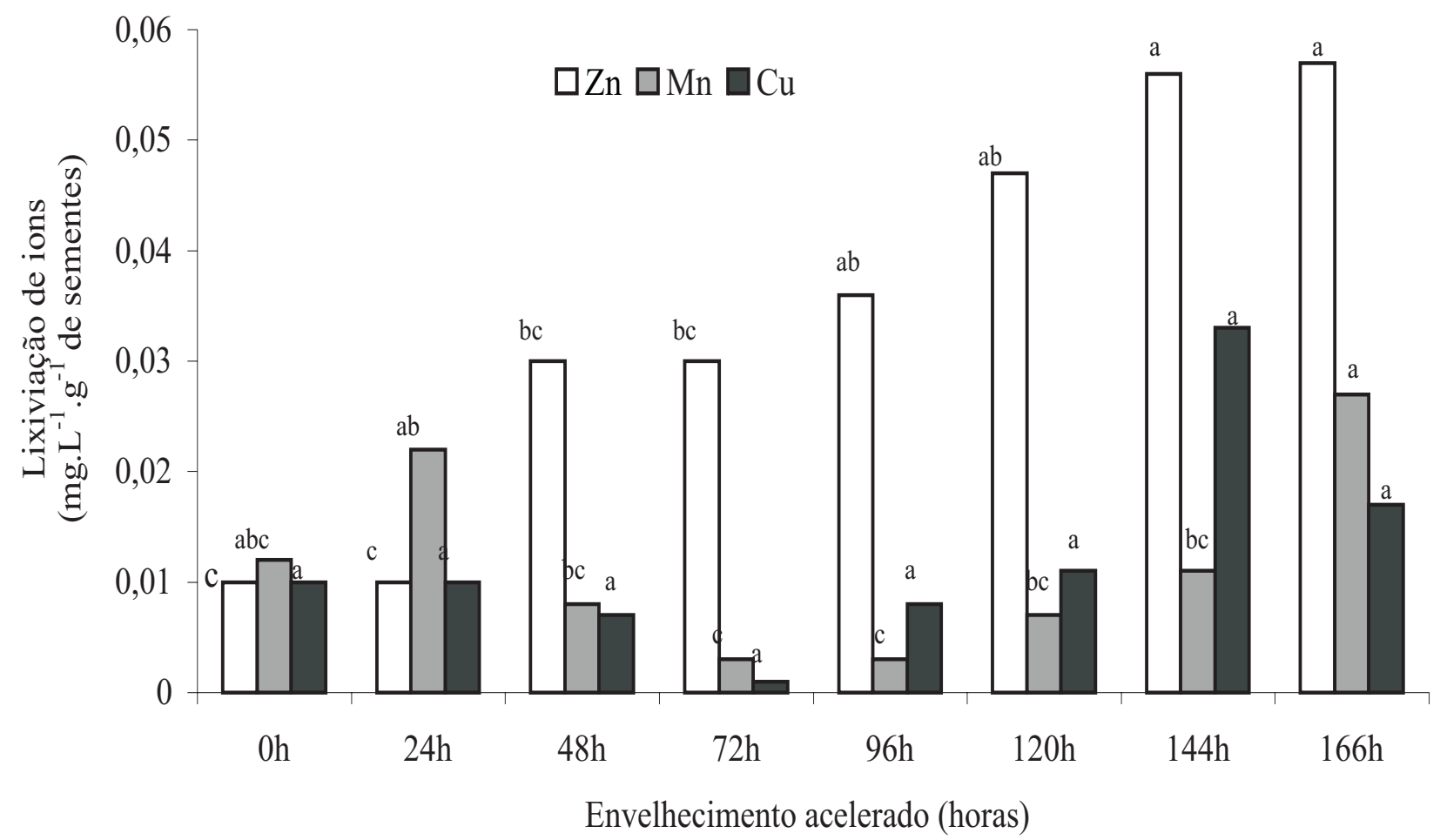

FIGURA 4. Lixiviação de íons Zn, Mn e Cu (mg.L-1 g de semente $\left.^{-1}\right)$ em sementes de milho BR 3123, submetidas a diferentes períodos de envelhecimento acelerado. Botucatu/SP, 2003. 


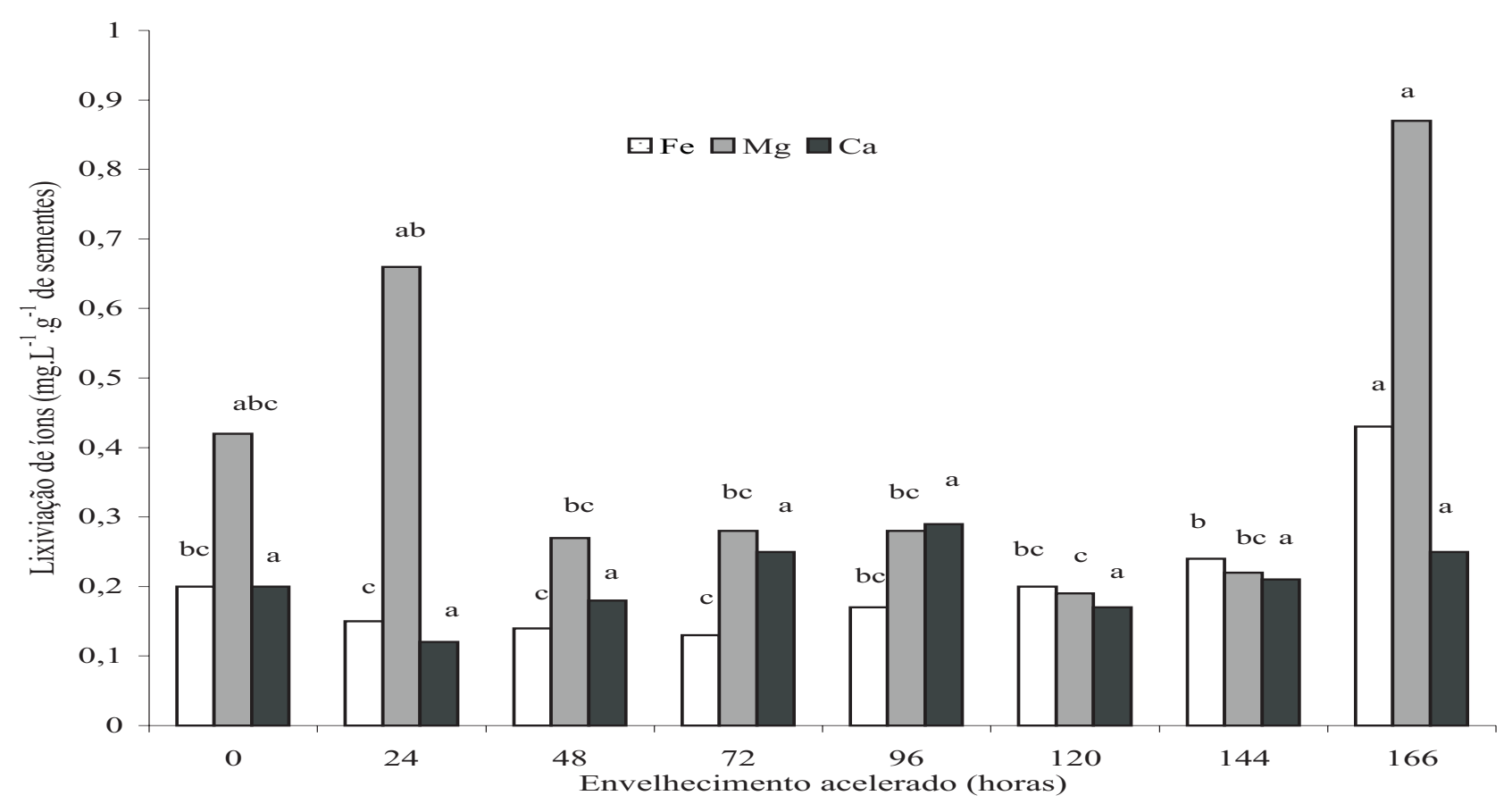

FIGURA 5. Lixiviação de íons Fe, Mg e Ca (mg.L ${ }^{-1}$.g de semente $\left.{ }^{-1}\right)$ em sementes de milho BR 3123, submetidas a diferentes períodos de envelhecimento acelerado. Botucatu/SP, 2003.

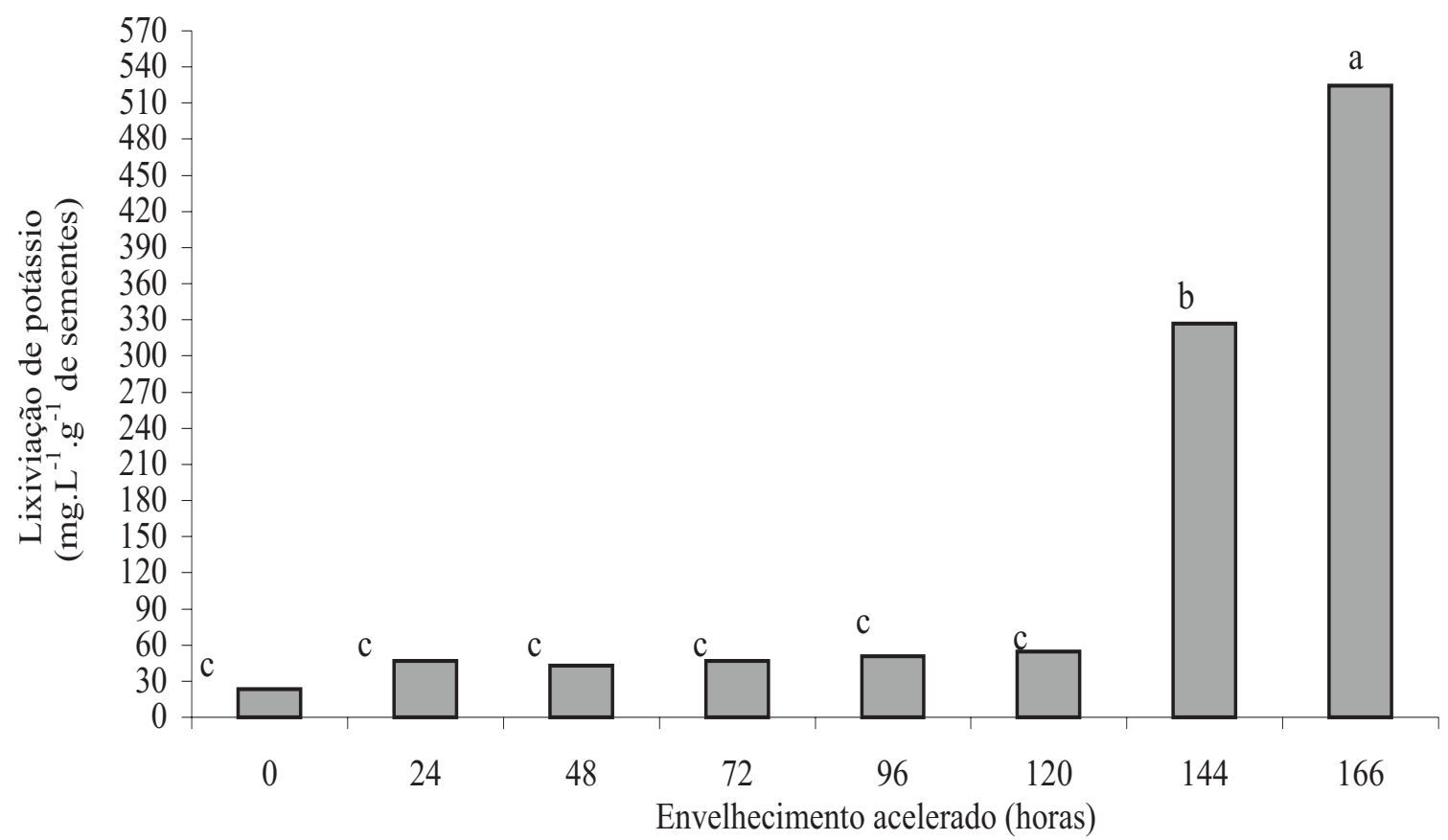

FIGURA 6. Lixiviação de íon $\mathrm{K}\left(\mathrm{mg} \cdot \mathrm{L}^{-1} \cdot \mathrm{g}\right.$ de semente $\left.{ }^{-1}\right)$ em sementes de milho BR 3123, submetidas a diferentes períodos de envelhecimento acelerado. Botucatu/SP, 2003. 
elemento na solução de embebição, sendo mais expressiva em sementes sem testa. Comportamento similar foi observado para condutividade elétrica e lixiviação de açúcares redutores. Os referidos autores concluíram, ainda, que a maior lixiviação de proteínas solúveis totais e compostos fenólicos foi obtida para sementes intactas. Esses compostos protegem os componentes celulares contra a oxidação, pois altos níveis de oxigênio podem reduzir a sobrevivência das sementes.

Em sementes de repolho, o aumento do período de envelhecimento ocasionou lixiviação de maiores quantidades de potássio e cloro, destacando-se o primeiro elemento (Loomis \& Smith, 1980). Dentre os íons estudados, o potássio tem merecido especial atenção por se tratar do principal íon em termos de quantidade lixiviada.

\section{CONCLUSÕES}

A elevação dos valores de condutividade elétrica e de lixiviação de proteínas solúveis totais ocorreu a partir de 72 horas de envelhecimento acelerado.

A lixiviação de potássio foi mais acentuada do que a dos íons cálcio, zinco, manganês, cobre, ferro e magnésio.

\section{REFERÊNCIAS}

ABDEL SAMAD, I. M.; PEARCE, R.S. Leaching of ions, organic molecules, and enzymes from seeds of peanut (Arachis hypogea L.) imbibing without testa or with intact testa. Journal of Experimental Botany, Oxford, v.29, n.112, p.1471-1478, 1978.

ALIZAGA, R.L.; MELLO, V.D.C.; SANTOS, D.S.B; IRIGON, D.L. Avaliação de testes de vigor em sementes de feijão e suas relações com emergência a campo. Revista Brasileira de Sementes, Brasília, v.12, n.2, p.44-58, 1990.

AOSA-ASSOCIATION OF OFFICIAL SEED ANALYSIS. Seed vigour testing handbook. East Lansing: AOSA, 1983. 88p.

BEWLEY, J.D. Membrane changes in seeds as related to germination and the turbatios resulting from deterioration in storage. In: McDONALD, M.B.; NELSON, C.J. (Ed) Physiology of seed deterioration. Winsconsin: 1986. p. 27-45.

BRASIL. Ministério da Agricultura e Reforma Agrária. Regras para análise de sementes. Brasília: SNDA/DNDV/CLAV, 1992. $365 \mathrm{p}$.

CHANHAN, K.P.; PURKAR, J.K.; BANERJEE, S.K. Ageing induced changes in seeds. Seed Research, v.12, n.1, p.56-68, 1984.

DIAS, D.C.S.F., MARCOS FILHO, J. Testes de vigor baseados na permeabilidade das membranas celulares: II. Lixiviação de potássio. Informatovo ABRATES, Brasília, v.5, n.1, p.37-41, 1995. FLOOD, R.G.; SINCLAIR, A. Fatty acid analysis of aged permeable and impermeable seed of Trifolium subtrraneum. Seed Science and Technology, Zürich, v.9, n.2, p.475-477, 1981.

HARRINGTON, J.F. Problems of seed storage. In: HEYDECKER, W.H. Seed ecology. Pennsylvania: The Pennsylvania State University Press, 1973. p.251-265.

HALLOIN, J.M. Solute loss from deteriorated cotton seed: relationshep between deterioratin, seed moisture, and solute loss. Crop Science, Madison, v.15, n.1, p.11-15, 1975.

LOOMIS, E.L.; SMITH, O. E., The effect of artificial ageing on concentration of $\mathrm{Ca}, \mathrm{Mg}, \mathrm{Mn}, \mathrm{K}$ and $\mathrm{Cl}$ in imbibing cabbage seed. Journal of American Society of Horticultural Science, S. Joseph, v.105, n.5, p.647-650, 1980.

LOWRY, O.H., ROSEBROUGH, N.J., FARR, A.L., ET AL. Protein measurement with Folin-phenol reagent. Journal of Biological Chemistry, Bethesda, v.193, n.3, p.265-275. 1951.

MARCOS FILHO, J. Testes de envelhecimento acelerado. In: KRZYZANOWSKY, F.C.; VIEIRA, R.D.; FRANÇA-NETO, J.B. (Ed). Vigor de sementes: conceitos e testes. Londrina: ABRATES, 1999. p.1-24.

MARCOS FILHO, J.; SILVA, W.R.; NOVEMBRE, A.D.C.L.; CHAMMA, H.M.C.P. Estudo comparativo de métodos para avaliação da qualidade fisiológica de sementes de soja, com ênfase ao teste de condutividade elétrica. Pesquisa Agropecuária Brasileira, Brasilia, v. 25, n.12, p.1805-1815, 1990.

MATTHEWS, S.; POWELL, A.A. Electrical conductivity test. In: PERRY, D.A. Handbook of vigour test methods. Zürich: ISTA, 1981, p. 37-42.

McDONALD Jr., M.B.; WILSON, D.O. ASA-610 ability to detect changes in soybean seed quality. Journal of Seed Technology, Lansing, v.5, n.1, p.56-66, 1980.

MCKERSIE, B.D.; STINSON, R.H. Effect of dehydration on leakage and membrane structure in Lotus corniculatus L. seeds. Plant Physiology, Rockville, v.66, n.2, p.316-320, 1980.

OHLROGGE, J.B.; KERNAN, T.P. Oxygen dependent aging of seeds. Plant Physiology, Rockville, v.70, n.3, p.791-796, 1982.

OLIVEIRA, J.A. Correlação entre a evolução de hexanal e de aldeídos totais, a lixiviação de íons e o potencial de germinação de sementes de soja (Glycine max (L.) Merrill). 1990. 79f. Dissertação (Mestrado em Fitotecnia) - Universidade Federal de Viçosa, Viçosa, 1990.

WOODSTOCK, L.W.; FURMAN, K.; LEFFLER, H.R. Relationship between weathering deterioration and germination, respiratory metabolism, and mineral leaching from cotton seeds. Crop Science, Madison, v.25, n.3, p.459-466, 1985.

WOODSTOCK, L. W. Seed imbibition: a critical period for successful germination. Journal of Seed Technology, Lansing, v.12, n.1, p.1-15, 1988

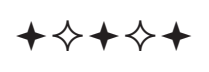

